\title{
Determination of binary mixture of ibuprofen and famotidine by different spectrophotometric methods
}

\author{
Ahmed Aqeel Al-Shibly *, Hany Hunter Monir, \\ Mohamed Refaat El-Ghobashy and Sawsan Mohamed Amer \\ Analytical Chemistry Department, Faculty of Pharmacy, Cairo University, 11562, Cairo, Egypt \\ * Corresponding author at: Analytical Chemistry Department, Faculty of Pharmacy, Cairo University, 11562, Cairo, Egypt. \\ Tel.: +20.11.56403337. Fax: +20.11.56403337. E-mail address: ahmedalshibly@yahoo.com (A.A. Al-Shibly).
}

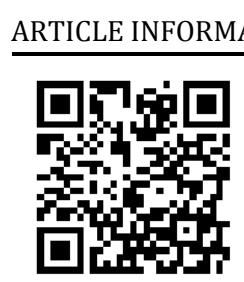

DOI: 10.5155/eurjchem.7.2.161-165.1407

\section{ABSTRACT}

Four simple and specific spectrophotometric methods were developed and validated for the simultaneous determination of binary mixture of ibuprofen and famotidine, using unified regression equation. The proposed spectrophotometric procedures including, derivative ratio, ratio subtraction, dual wavelength and mean centering of ratio spectra do not require any separation steps. Accuracy, precision and linearity ranges of the proposed methods were determined and the specificity was assessed by analysing synthetic mixtures of both drugs. The methods were applied to a pharmaceutical formulation and the results obtained showed that there is no significant difference between the proposed methods and the reported one regarding both accuracy and precision.

Received: 07 February 2016

Received in revised form: 08 March 2016

Accepted: 12 March 2016

Published online: 30 June 2016

Printed: 30 June 2016

\section{KEYWORDS}

Ibuprofen

Famotidine

Ratio spectra

Dual wavelength

Ratio subtraction

Spectrophotometric method

Cite this: Eur. J. Chem. 2016, 7(2), 161-165

\section{Introduction}

Ibuprofen (IBU) (Figure 1a) is a non-steroidal antiinflammatory, analgesic and antipyretic drug [1]. It inhibits the cyclo-oxygenase enzyme which catalyses the transformation of unsaturated fatty acids to prostaglandins. This inhibition of the prostaglandin synthesis is the cause for the analgesic, antipyretic, and anti-inflammatory action of the drug. It is well absorbed orally and more than $99 \%$ protein bound, extensively metabolized in the liver and little is excreted unchanged [2].

Famotidine (FAM) (Figure 1b) is a competitive histamine H2-receptor antagonist. Its main pharmacodynamic effect is the inhibition of gastric secretion [3]. It serves as an alternative to proton-pump inhibitors [4].

Several methods have been reported for the simultaneous determination of IBU and FAM. These methods include HPLC [5-12], HPTLC [7] spectrophotometric methods [13,14]. The aim of this work is to develop and conduct different application of the spectrophotometric methods for resolving the binary mixture of IBU and FAM, either in pure form or in their pharmaceutical preparation without preliminary separation steps using unified regression equation [15].<smiles>CC(C)Cc1ccc(C(C)C(=O)O)cc1</smiles><smiles>NC(N)=Nc1nc(CSCC/C(N)=N/S(N)(=O)=O)cs1</smiles>

Figure 1. Chemical structure of (a) ibuprofen and (b) famotidine.

\section{Experimental}

\subsection{Instrumentations}

Spectrophotometric measurements were carried out on Shimadzu 1650 UV-PC spectrophotometer, using $1.00 \mathrm{~cm}$ quartz cells. Scans were carried out in the range from $200-400$ 
$\mathrm{nm}$ at $0.1 \mathrm{~nm}$ intervals. For mean centering of ratio spectra (MCR) computations, Matlab ${ }^{\circledR} 7$ was used along with PLStoolbox.

\subsection{Chemicals and reagents}

Sodium hydroxide and methanol were supplied from ElNasr Chemicals Company (ADWIC, Egypt). Ibuprofen was kindly supplied by Western Pharmaceutical Industries, China, its purity was labelled to be $99.6 \%$ based on the company's analysis certificate. Famotidine was kindly supplied by Kahira Company, Cairo, Egypt. Its purity was labelled to be $99.8 \%$ based on the company's analysis certificate. Duexis ${ }^{\circledR}$ was kindly supplied from Horizon Pharma Industry and taken from Rite Aid Pharmacy (BN. 91206), 531 North Glendale Avenue, Glendale, CA, USA. Each tablet contains $800 \mathrm{mg}$ ibuprofen and $26.6 \mathrm{mg}$ famotidine.

\subsection{Standard solutions}

Stock solutions of IBU and FAM $(1000 \mu \mathrm{g} / \mathrm{mL})$ were prepared by dissolving $100 \mathrm{mg}$ of both drugs in $100 \mathrm{~mL}$ of 0.1 $\mathrm{M} \mathrm{NaOH}$. Working solution of IBU is the same stock solution. Working solution of FAM $(100 \mu \mathrm{g} / \mathrm{mL})$ was prepared from stock solution of FAM by dilution with $0.1 \mathrm{M} \mathrm{NaOH}$.

\subsection{Procedures}

\subsubsection{Spectral characteristics}

The absorption spectrum of $300 \mu \mathrm{g} / \mathrm{mL}$ of IBU and 18 $\mu \mathrm{g} / \mathrm{mL}$ FAM, both separately and in a laboratory mixture in 0.1 $\mathrm{N} \mathrm{NaOH}$ were scanned over the range $200-400 \mathrm{~nm}$ against 0.1 $\mathrm{N} \mathrm{NaOH}$ as a blank.

\subsubsection{Linearity}

Standard solutions containing $50-600 \mu \mathrm{g} / \mathrm{mL}$ of IBU and 2$22 \mu \mathrm{g} / \mathrm{mL}$ FAM were prepared separately in $0.1 \mathrm{~N} \mathrm{NaOH}$. The absorption spectra of the resulting solution were measured in the range of $200-400 \mathrm{~nm}$ and stored in the computer.

\subsubsection{Construction of calibration curves}

\subsubsection{Derivative ratio method (DRM)}

The stored spectra of IBU solutions $(50-600 \mu \mathrm{g} / \mathrm{mL})$ were divided by the absorption spectrum of standard solution of FAM $(18 \mu \mathrm{g} / \mathrm{mL})$, and the first derivative of the resulting spectra were obtained. The regression equation between the IBU concentration and the first derivative at $267 \mathrm{~nm}$ was computed.

\subsubsection{Ratio subtraction method (RSM)}

The stored spectra of laboratory prepared mixtures of IBU solutions $(50-600 \mu \mathrm{g} / \mathrm{mL})$, and FAM $(2-22 \mu \mathrm{g} / \mathrm{mL})$ were divided by the absorption spectrum of standard solution of FAM $(18 \mu \mathrm{g} / \mathrm{mL})$, and the constant value at a plateau region 286-298 nm was subtracted from the resulted spectra, after that the resulting spectra were multiplied by the FAM (18 $\mu \mathrm{g} / \mathrm{mL}$ ). The regression equation between the IBU spectrum at $264 \mathrm{~nm}$ and the corresponding IBU standard concentrations was computed.

\subsubsection{Dual wavelength method (DWM)}

The absorbance of IBU solutions at 243.6 and $261.4 \mathrm{~nm}$ were measured and recorded. The difference between these two points was computed. The regression equation relating the difference between absorbance of IBU at the specified wavelengths and corresponding IBU concentrations was computed.

\subsubsection{Mean centering of ratio spectra method (MCM)}

The stored spectra of IBU solutions (50-600 $\mu \mathrm{g} / \mathrm{mL})$ were divided by the absorption spectrum of standard solution of FAM $(18 \mu \mathrm{g} / \mathrm{mL})$. The ratio spectra obtained were exported to Matlab for subsequent calculation, then the first order absorption spectra of IBU were divided by the first order absorption spectrum of standard solution of FAM $(18 \mu \mathrm{g} / \mathrm{mL})$, the obtained ratio spectrum was then mean centred at $290 \mathrm{~nm}$ $v s$ the corresponding concentrations of IBU and the regression equations were computed.

\subsection{Analysis of laboratory prepared mixtures}

For preparation of laboratory prepared mixtures, aliquots equivalent to $50-600 \mu \mathrm{g}$ of IBU and 2-22 $\mu \mathrm{g}$ of FAM were accurately transferred from their working solutions (IBU 1000 $\mu \mathrm{g} / \mathrm{mL}$ and FAM $100 \mu \mathrm{g} / \mathrm{mL}$, respectively) into a series of 10 $\mathrm{mL}$ volumetric flasks and the volume was completed with 0.1 $\mathrm{N} \mathrm{NaOH}$. The spectra of the prepared mixtures were scanned from $200-400 \mathrm{~nm}$ and stored in the computer. The procedure detailed under linearity for each method was followed and then IBU and FAM concentration was calculated using the corresponding regression equation.

\subsection{Application to pharmaceutical formulation}

Duexis $®$; each tablet claimed to contain $800 \mathrm{mg}$ of IBU and $26.6 \mathrm{mg}$ of FAM. Five tablets were weighted, grinded well in mortar. Then a weight from the powdered tablets equivalent to one tablet was taken and sonicated in $0.01 \mathrm{~N} \mathrm{NaOH}$ for 30 min. Then, the suspension was filtered and transferred to 100 $\mathrm{mL}$ volumetric flask and completed with $0.01 \mathrm{~N} \mathrm{NaOH}$. Appropriate dilution was made to get a mixture of $160 \mu \mathrm{g} / \mathrm{mL}$ IBU and $5.32 \mu \mathrm{g} / \mathrm{mL}$ FAM. Standard addition techniques was performed. The procedure detailed under linearity for each method was followed and then IBU and FAM concentration was calculated using the corresponding regression equation. When carrying out the standard addition technique, the tablet powder and pure IBU and FAM were mixed well together before proceeding in the above mentioned procedures.

\section{Results and discussion}

The main problem of spectrophotometric multicomponent analysis is the simultaneous determination of two or more compounds in the same mixture without preliminary separation [16]. The main task of this work is to establish precise, simple, sensitive and accurate spectrophotometric analytical methods for simultaneous determination of IBU and FAM in their bulk powders and pharmaceutical dosage form with satisfactory precision and accuracy [17]. As well, to construct a statistical comparison between the ability of the proposed methods to determine both drugs in their pure form, laboratory prepared mixture and in their pharmaceutical formulations. Upon scanning the absorption spectra of IBU and FAM in methanol (Figure 2), it was found that FAM can be determined at $286.8 \mathrm{~nm}$ without interference from IBU, while no wavelength was found suitable for IBU determination without FAM interference. Therefore, four spectrophotometric methods were applied for simultaneous determination of IBU and FAM.

For the choice of suitable divisor for derivative ratio, ratio subtraction and mean centering methods, several concentrations of FAM were tried until we got the divisor of choice which is $18 \mu \mathrm{g} / \mathrm{mL}$. For derivative ratio method, IBU spectra were divided by FAM divisor as shown in Figure 3, then first derivative spectrum was obtained as shown in Figure 4. 


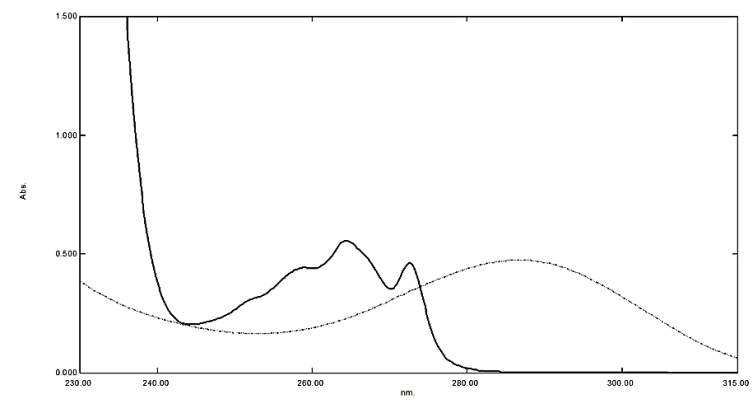

Figure 2. Zero order spectrum of ibuprofen $300 \mu \mathrm{g} / \mathrm{mL}$ (__ ) and famotidine $10 \mu \mathrm{g} / \mathrm{mL}(\ldots)$.

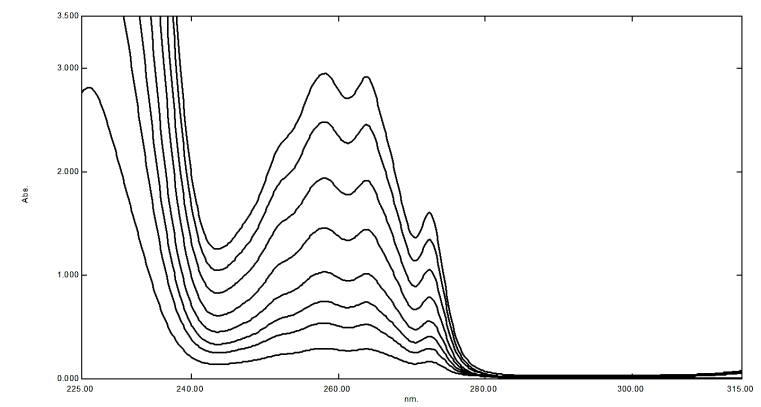

Figure 3. Ratio spectra of IBU $(50-600 \mu \mathrm{g} / \mathrm{mL})$ using $(18 \mu \mathrm{g} / \mathrm{mL}) \mathrm{FAM}$ as a divisor.

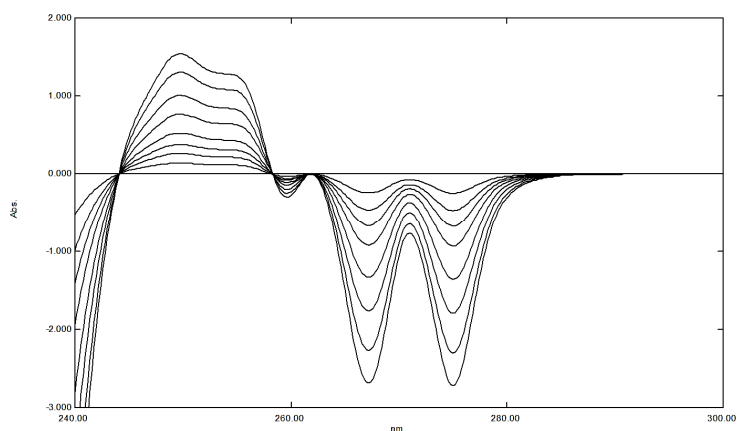

Figure 4. First derivative of ratio spectra IBU $50-600 \mu \mathrm{g} / \mathrm{mL}$ using (18 $\mu \mathrm{g} / \mathrm{mL}$ ) FAM as a divisor.

For ratio subtraction method, laboratory prepared mixtures were prepared as mentioned above, dividing laboratory prepared mixtures over FAM divisor as shown in Figure 5, subtraction the constant value at a plateau region (286-298 nm) as shown in Figure 6 then multiplication the spectra by FAM divisor to obtain spectra of IBU as shown in Figure 7.

For dual wavelength method, FAM spectrum at 243.6 and $261.4 \mathrm{~nm}$ have the same measure, otherwise IBU spectrum at the same points have difference in measurement, a regression equation was computed as shown Figure 2.

The mean centering method at $290.0 \mathrm{~nm}$, IBU concentrations over FAM ratio spectra were calculated using computer program as mentioned in Figure 8.

The mixture of ibuprofen and famotidine in methanol gives two peaks at 264.0 and $266.0 \mathrm{~nm}$, respectively, instead of $286.0 \mathrm{~nm}\left(\lambda_{\max }\right.$ of FAM), this observed hypsochromic shift was due to quarternerization of tertiary amine of FAM in methanol solvent. But in $0.1 \mathrm{~N} \mathrm{NaOH}$ solvent show absorbance at 264.0 and $286.8 \mathrm{~nm}$ for IBU and FAM, respectively, and did not show any solvent effect on the wavelength of the mixture, so we used $0.1 \mathrm{~N} \mathrm{NaOH}$ instead of methanol solvent to avoid the hypsochromic shift problem.

During application process of pharmaceutical formulation, we found that it is so difficult to make a filtration of the tablet contents, if we used a $0.1 \mathrm{~N} \mathrm{NaOH}$ solvent, we found that switching the solvent to $0.01 \mathrm{~N} \mathrm{NaOH}$ makes the filtration process easier and accurate.

For all the proposed methods, the statistical parameters of the regression equations and the concentration ranges are shown in Table 1 . Table 1 shows that the proposed methods were applied for the determination of pure drugs and satisfactory results were obtained. Standard addition technique was performed as mentioned in Table 2. The proposed method was successfully applied to the analysis of IBU and FAM in their laboratory prepared mixtures and in tablet dosage form, Table 3 .

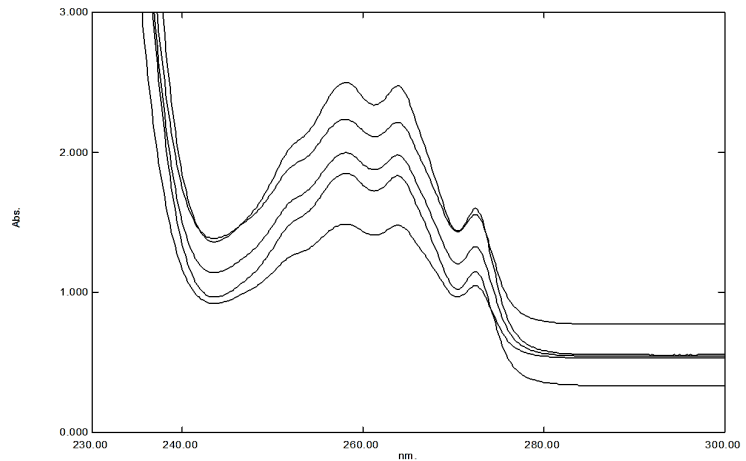

Figure 5. Obtained spectra of IBU after division of five laboratory prepared mixtures by FAM $18 \mu \mathrm{g} / \mathrm{mL}$ as a divisor.

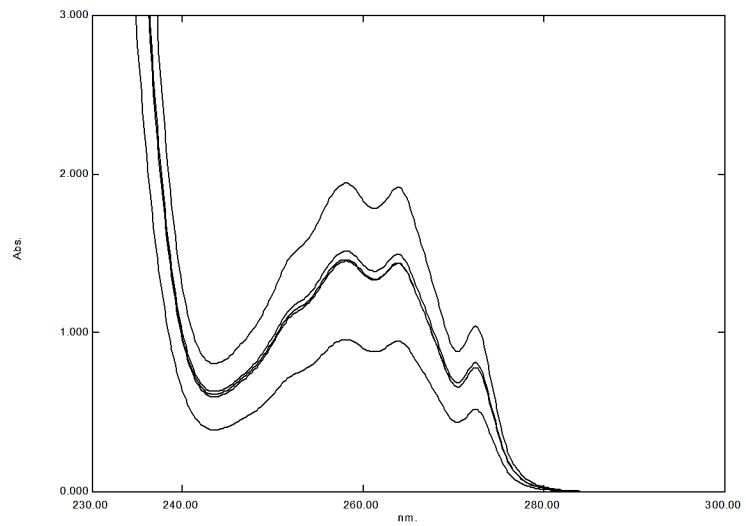

Figure 6. Obtained spectra of IBU after division of five laboratory prepared mixtures by FAM $18 \mu \mathrm{g} / \mathrm{mL}$ as a divisor and subtraction of the constant value.

\subsection{Method validation}

Validation was done according to ICH recommendations [18,19].

\subsubsection{Linearity}

The linearity of the methods was evaluated by analyzing five concentrations of IBU and six concentrations of FAM ranging from $50-600 \mu \mathrm{g} / \mathrm{mL}$ and $2-22 \mu \mathrm{g} / \mathrm{mL}$, respectively. Each concentration was repeated three times. The assay was performed according to the experimental conditions previously mentioned. The linear equations were summarized in Table 1. 
Table 1. Regression parameters and results of determination of pure samples of IBU and FAM by the proposed spectrophotometric methods.

\begin{tabular}{|c|c|c|c|c|c|}
\hline \multirow[t]{2}{*}{ Parameters } & \multirow{2}{*}{ DRM } & \multirow[b]{2}{*}{ RSM } & \multirow[b]{2}{*}{ DWM } & \multirow[b]{2}{*}{ MCM } & \multirow{2}{*}{$\begin{array}{l}\text { Famotidine } \\
\text { FAM c }\end{array}$} \\
\hline & & & & & \\
\hline Linearity & $50-600 \mu \mathrm{g} / \mathrm{mL}$ & $50-600 \mu \mathrm{g} / \mathrm{mL}$ & $50-600 \mu \mathrm{g} / \mathrm{mL}$ & $50-600 \mu \mathrm{g} / \mathrm{mL}$ & $2-22 \mu \mathrm{g} / \mathrm{mL}$ \\
\hline Slope & 0.0044 & 0.0018 & 0.0008 & 0.0036 & 0.00455 \\
\hline Intercept & 0.0096 & 0.0095 & -0.0003 & -0.3608 & 0.0117 \\
\hline Correlation coefficient $(r)$ & 0.9998 & 0.9997 & 0.9997 & 0.9992 & 0.9997 \\
\hline Mean \pm SD & $101.14 \pm 0.680$ & $100.49 \pm 1.280$ & $101.15 \pm 0.997$ & $99.72 \pm 2.230$ & $100.21 \pm 1.774$ \\
\hline RSD & 0.640 & 1.273 & 1.079 & 2.240 & 1.770 \\
\hline \multicolumn{6}{|l|}{$\overline{\text { Precision (\%RSD) }}$} \\
\hline Repeatability a & \pm 0.520 & \pm 1.154 & $3 \pm 2.14$ & $0 \pm 2.16$ & \pm 0.841 \\
\hline Intermediate precision $\mathrm{b}$ & \pm 0.540 & \pm 1.162 & \pm 2.153 & \pm 2.190 & \pm 0.860 \\
\hline
\end{tabular}

a Intraday precision (the \%RSD of 3 different concentrations for IBU and FAM) / 3 replicates each, within the same day).

b Interday precision (the \%RSD of 3 different concentrations for IBU and FAM) / 3 replicates each, repeated on 3 successive days)

c Zero order at $286.6 \mathrm{~nm}$.

Table 2. Determination of IBU and FAM in pharmaceutical formulation by the proposed methods and application of standard addition technique.

\begin{tabular}{|c|c|c|c|c|c|}
\hline \multirow{2}{*}{$\begin{array}{l}\text { Pharmaceutical formulation } \\
\text { Duexis® Tablets BN. } 91206\end{array}$} & \multicolumn{4}{|l|}{ Ibuprofen } & \multirow{2}{*}{$\begin{array}{l}\text { Famotidine } \\
\text { (At } 286.6 \mathrm{~nm})\end{array}$} \\
\hline & DRM & RSM & DWM & MCM & \\
\hline Found $\%{ }^{a} \pm S D$ & $99.72 \pm 1.14$ & $100.05 \pm 1.30$ & $100.79 \pm 0.94$ & $100.39 \pm 1.02$ & $100.74 \pm 0.99$ \\
\hline \multirow[t]{3}{*}{ Pure added $(\mu \mathrm{g} / \mathrm{mL})$} & 100 & 100 & 100 & 100 & 2.5 \\
\hline & 200 & 200 & 200 & 200 & 5 \\
\hline & 300 & 300 & 300 & 300 & 7 \\
\hline \multirow[t]{3}{*}{ Recovery \% b } & 99.25 & 100.60 & 99.64 & 100.54 & 99.60 \\
\hline & 100.60 & 99.76 & 100.50 & 101.6 & 98.76 \\
\hline & 101.74 & 101.6 & 101.6 & 99.80 & 100.6 \\
\hline Mean \pm SD & $100.53 \pm 1.24$ & $100.65 \pm 0.92$ & $100.58 \pm 0.98$ & $100.55 \pm 0.93$ & $101.65 \pm 1.16$ \\
\hline
\end{tabular}

a Average of three determinations.

b Average of three determinations.

Table 3. Determination of IBU and FAM in laboratory prepared mixtures by suggested spectrophotometric methods. Pharmaceutical Ibuprofen

$300 \mu \mathrm{g} / \mathrm{mL}$ IBU : $6 \mu \mathrm{g} / \mathrm{mL}$ FAM $300 \mu \mathrm{g} / \mathrm{mL}$ IBU : $10 \mu \mathrm{g} / \mathrm{mL}$ FAM $300 \mu \mathrm{g} / \mathrm{mL}$ IBU : $14 \mu \mathrm{g} / \mathrm{mL}$ FAM $200 \mu \mathrm{g} / \mathrm{mL}$ IBU : $10 \mu \mathrm{g} / \mathrm{mL}$ FAM $400 \mu \mathrm{g} / \mathrm{mL}$ IBU : $10 \mu \mathrm{g} / \mathrm{mL}$ FAM $\underline{\mathrm{Mean} \pm \mathrm{SD}}$

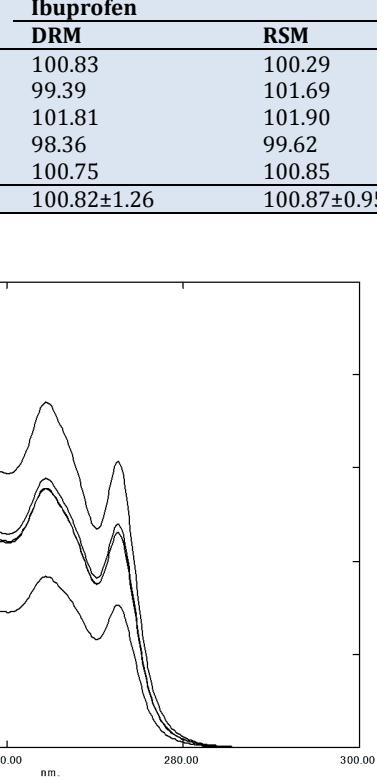

Figure 7. Obtained spectra of IBU after division of five laboratory prepared mixtures by FAM $18 \mu \mathrm{g} / \mathrm{mL}$ as a divisor, subtraction of the constant value, then multiplication by FAM $18 \mu \mathrm{g} / \mathrm{mL}$.

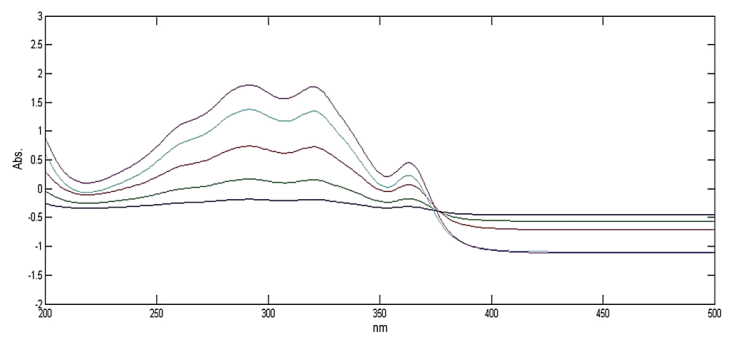

Figure 8. Mean centering of IBU $(50-600 \mu \mathrm{g} / \mathrm{mL})$ at $290 \mathrm{~nm}$ using FAM 18 $\mu \mathrm{g} / \mathrm{mL}$ as divisor.

\subsubsection{Accuracy}

The accuracy of the results was checked by applying the proposed methods for determination of different blind samples of IBU and FAM. The concentrations were obtained from the corresponding regression equations. From which the percentage recoveries suggested good accuracy of the proposed methods, Table 1.

\subsubsection{Range}

The calibration range was established through considerations of the practical range necessary according to adherence to Beer's law and the concentration of IBU and FAM present in the pharmaceutical preparations to give accurate precise and linear results, Table 1.

\subsubsection{Selectivity}

Selectivity of the methods was achieved by the analysis of different laboratory prepared mixtures of IBU and FAM within the linearity range. Satisfactory results were obtained and shown in Table 1.

\subsubsection{Precision}

\subsubsection{Repeatability and reproducibility}

They were determined using three concentrations of each of IBU $(100,200,500 \mu \mathrm{g} / \mathrm{mL})$ and FAM $(2,10,18 \mu \mathrm{g} / \mathrm{mL})$ which were analysed three times intra-daily and inter-daily on three different days using the proposed methods. The relative standard deviations were calculated, Table 1. 
Table 4. Statistical analysis of the proposed methods and the reported method of ibuprofen and famotidine in their pure powdered form.

\begin{tabular}{llllllll} 
Parameter & IBU & & & & & FAM \\
\cline { 2 - 7 } & DRM & RSM & DWM & MCM & Reported method [22] & Zero order & Reported method [22] \\
\hline Mean & 101.14 & 100.49 & 101.15 & 99.72 & 100.20 & 100.21 & 100.74 \\
\pm SD & \pm 0.680 & \pm 1.280 & \pm 0.997 & \pm 2.230 & \pm 1.130 & \pm 1.774 & \pm 1.053 \\
$n$ & 5 & 5 & 5 & 5 & 5 & 6 & 3.140 \\
Variance & 0.462 & 1.638 & 0.994 & 4.970 & 1.270 & $0.77(2.228)$ \\
$t$-test & $1.56(2.306)$ & $0.42(2.306)$ & $1.46(2.306)$ & $0.59(2.306)$ & & 1.108 \\
F-test & $2.74(6.39)$ & $1.28(6.39)$ & $1.27(6.39)$ & $3.91(6.39)$ & & $2.83(5.05)$ \\
\hline
\end{tabular}

The figures in parenthesis are the corresponding theoretical values at $p=0.05$.

\subsubsection{Stability}

IBU and FAM working solutions in methanol showed no spectrophotometric changes up to 4 weeks when stored at 4 ${ }^{\circ} \mathrm{C}$.

\subsection{Application of the proposed methods for assay of tablets}

The proposed UV methods were applied for the determination of IBU and FAM in their combined pharmaceutical formulation Duexis $\AA^{\circledR}$ tablets and the results are shown in Table 2. The good percentage recoveries confirm the suitability of the proposed methods for the routine determination of these components in their combined formulation.

Statistical analysis of the proposed methods and the reported method [20] was done as mentioned in Table 4 showing no significant difference between them.

\section{Conclusion}

In this work, four simple, sensitive and precise spectrophotometric methods were applied for the simultaneous analysis of binary mixture of ibuprofen and famotidine with minimum manipulation steps. They do not need any sophisticated apparatus or a special program and could be easily applied in quality control laboratories, either in their pure bulk powders and in dosage form [14].

\section{References}

[1]. O'Neil, M. J. The Merck Index - An Encyclopedia of Chemicals, Drugs, and Biologicals. 13 $3^{\text {th }}$ Edition, Whitehouse Station, NJ: Merck and Co., Inc., 2001.

[2]. Katzung, B. G.; Furst, D. E. Basic and clinical pharmacology, $7^{\text {th }}$ ed., Appliton and Lang Stamford, Connecticut, 1998.

[3]. Elzanfaly, E. S.; H. E. Zaazaa.; Soudi, A. T.; Salem, M. Y. Acta Chim. Slov. 2015, 62, 45-51.

[4]. Brophy, G. M.; Bidwell, K. L. Neurocrit. Care 2010, 13, 176-181.

[5]. Kumar, S. A.; Debnath, M.; Rao, J. V. L. N. S.; Sankar, D. G. Int. J. Pharm. Sci. Res. 2014, 5(9), 3829-3839.

[6]. Gracy, S.; Kumar, S. A.; Debnath, M.; Rao, J. V. L. N. S.; Sankar, D. G.; Mounika, T. A. Int. J. Pharm. Sci. Res. 2014, 5(4), 300-305.

[7]. Sekhar, V. R.; Reddy, Y. P.; Ramalingam, P.; Theja, D. H. Der. Phar. Sinica 2013, 4(2), 160-170.

[8]. Shah, D. A.; Suthar, D. J.; Baldania, S. L.; Chhalotiya, U. K.; Bhatt, K. K. ISRN Anal. Chem. 2012, 2012, Article ID 674392, 1-5.

[9]. Nyola, N.; Jeyabalan G. S. J. Appl. Pharm. Sci. 2012, 2(5), 79-83.

[10]. Ahirrao, V. K.; Pawar, R. P. Res. J. Pharm. Sci. 2013, 2(4), 1-9.

[11]. Krishnaveni, G.; Sathyannarayana, P. V. V. Int. J. Pharma Bio Sci. 2013, 4(3), 655-662.

[12]. Algobahi, K. M.; Younis, Y. M. H. Int. J. Res. Pharm. Sci. 2012, 2(3), 6980.

[13]. Prasad, P. R.; Bhuveneswari, K.; Murarilal, M.; Rajani, K. Der Pharmacia Let. 2015, 7(1), 232-237.

[14]. Wani, Y. B.; Patil, D. D. Int. J. Pharm. Pharm. Sci. 2013, 5(3), 358-363.

[15]. Lotfy, H. M.; Hegazy, M. A. M. Spectrochim. Acta A 2013, 113, 107114.

[16]. Fayez, Y. M. Spectrochim. Acta A 2014, 132, 446-451.

[17]. Lotfy, H. M.; Hegazy, M. A. M.; Abdel-Gawad, S. A. N. Eur. J. Chem. 2013, 4(4), 414-421.

[18]. Validation of Analytical Procedures: Text and Methodology Q2 (R1), ICH, 1997.

[19]. Abdel-Aleem, E. A.; Hegazy, M. A.; Sayed, N. W.; Abdelkawy, M.; Abdelfatah, R. M. Spectrochim. Acta A 2015, 136, 707-713.

[20]. Zaazaa, H. E.; Elzanfaly, E. S.; Soudi, A. T.; Salem, M. Y. Spectrochim. Acta $A$ 2015, 143, 251-255. 